International Review of Research in Open and Distributed Learning Volume 16, Number 4

October - 2015

\title{
Supporting Access to Open Online Courses for Learners of Developing Countries
}

Kwame Nti

University of Georgia, USA

\begin{abstract}
This paper examines how access to, and use of, open online courses may be enhanced for learners of developing countries from a learner perspective. Using analysis of the open education concept, factors that affect access to open educational resources content, and universal standards for delivering online learning, the author demonstrates that the open education concept, access, and participation in open online courses follow a three-level relationship. This relationship is affected by technological, economic, and more importantly, social factors, all of which play dual and opposite roles. The open education concept forms the foundation of the three-level relationship, while access maintains a central role from which participation, including use, repurposing, and redistribution of resources depend. The submission is that the relationship among openness, access, and participation should be a major consideration for producers and providers of open online courses who seek to support access for learners of developing countries.
\end{abstract}

Keywords: Open Educational Resources, Open Online Courses, Access, Social Factors, Developing Countries

\section{Introduction}

\section{Open Education}

The open education concept, through its offering of educational content from some of the most respected institutions of the world, holds promise to provide quality education to a world population group that possibly stands to benefit immensely. Among such world populations include developing countries. Open education is a concept that seeks to promote educational approaches and learning processes that caters to the particular needs of the learner (Kanwar, Uvalić-Trumbić, \& Butcher, 2011). Open education is about removing barriers to learning and providing students with the freedom to choose what, where, how, when, and at what pace to learn 
(Bissell, 2009; Kamper \& Plessis, 2013). For learners of developing countries, open education also involves removing barriers that limit their capacity to access and benefit from freely available quality higher educational offerings that could help contribute to developing their economic and social well-being (International Association of Universities, 2006). The use of open educational resources is a primary means for supporting open education (Kanwar et al., 2011).

\section{Open Educational Resources}

The United Nations Educational, Scientific and Cultural Organization (UNESCO) (2012) defines open educational resources (OER) as "teaching, learning and research materials in any medium, digital or otherwise, that reside in the public domain or have been released under an open license that permits no-cost access, use, adaptation and redistribution by others with no or limited restrictions" (p. 1). Teaching, learning, and research materials include content such as full courses, lecture notes, textbooks, course plans, and instructional videos (Kanwar et al., 2011). Materials also include tools such as software as well as implementation resources such as design techniques and principles (Atkins, Brown, \& Hammond, 2007).

OER are considered a major avenue towards achieving a key part of the Universal Declaration of Human Rights (UNESCO, 2002), which indicates that everyone has the right to education and for any interested person, quality education must be made generally available and equally accessible with no barriers or limitations (United Nations, 1948). Developing countries (DCs), historically, have been a prime target of the open education movement (UNESCO, 2002). For the OER movement to become relevant to their needs, developing countries should not be just spectators but participants (UNESCO, 2002). Efforts are being made to encourage scholars and institutions in DCs to actively participate in the production and delivery of OER content (Diallo, Thuo, \& Wright, 2013; Donkor, 2011). However, there is also the need to explore how we can make the myriad of currently available quality content more accessible and usable to learners in DCs who may have need for such content now. This is more important because of two major reasons.

First, a review of OER shows preference for the production of digital content (Bissell, 2009; Kanwar et al., 2011; OECD, 2007). OER, by design, are primarily delivered through information and communication technologies, an avenue that is relatively lacking in developing countries (ITU, 2014). Second, the majority of current OER content are produced and provided from contexts that are foreign to most developing countries (Organization for Economic Co-operation and Development [OECD], 2007; Rhoads, Berdan, \& Toven-Lindsey, 2013). OER content may be standalone, however, they usually are primary components of online courses which are commonly known as open online courses. Open online courses constitute a major learning object among OER. Against this background therefore, this paper proposes a framework from a learner's perspective, which the author agues should be a major consideration for producers and providers who seek to support access to, and use of, open online courses for learners of developing countries. 


\section{Open Online Courses}

Open Online Courses at the massive [macro] level (MOOC) or little [micro] level (mOOC) are OER content that are offered online mostly for free. Open online courses are full online courses that may comprise of instructional videos, lecture notes, quizzes, course projects, and discussion forums. I would like to categorize open online courses into two for the purpose of this discussion. Firstly, there are formal campus courses that were developed to meet specific curriculum needs at particular higher education institutions. Such courses may have been developed and taught with or without the intent to share them openly. Instructors of those courses and their institutions may then choose to share the courses and associated materials openly online. Examples include Utah State OpenCourseWare and MIT OpenCourseWare, an initiative that began in 2002 by the Massachusetts Institute of Technology (MIT) to publish virtually all its courses online. Secondly, there are courses that were designed from the outset as open education courses, with the sole purpose of making them freely and openly available online. Examples include OERu and Carnegie Mellon University's Open Learning Initiative. In this paper, the term open online courses refers mainly to the latter. Where relevant, clear references will be made to the former.

Open online courses are delivered through popular platforms such as Khan Academy, Coursera, Alison, OER Africa, Open Education Europa, FutureLearn, and YouTube EDU. This discussion refers to individuals, schools, organizations, and other institutions that design, develop, and deliver open online courses as producers. Providers include organizations that offer the platform for making open online courses available to the eventual user. Thus, MIT and Harvard University are considered producers while edX, the online platform for delivering their open online course offerings, is considered a provider. Khan Academy would be considered both a producer and provider because it both produces and provides the platform for delivering its open online courses. Open online courses usually attract students from all over the world, with numbers in the tens and sometimes hundreds of thousands. For example, as of 2014, Coursera reported over 22 million student users, over 100 partners or providers of courses, and 571 courses, all of which include instructional videos (Coursera, 2013, 2014). Khan Academy, which as of 2014, carried over 5,500 instructional videos, receives 10 million unique users a month (Murphy, Gallagher, Krumm, Mislevy, \& Hafter, 2014), has had learners completing over 2.5 billion lessons to date, and has over 500, oooo registered teachers worldwide who use the resource in their classrooms. Also, YouTube EDU, the primary education channel of YouTube, had about 25,800 subscribers of the university sub-channel alone.

The worldwide reach of content such as open online courses form one basis that proponents use to advance the OER concept as socially responsible; providing equitable and universal access to knowledge; and potentially, aiding in the alleviation of international poverty (Rhoads et al., 2013; Richter \& McPherson, 2012). A worldwide reach, however, does not necessarily translate into universal accessibility. Potential end-users of open online courses also include students who may be foreign to the context of production and delivery of content as it relates to social, technological, 
and economic factors. A significant number of those students reside in the most needy regions of the world with regards to accessible educational opportunities and economic development (UNESCO, 2011). Developing countries have mostly been at the receiving end of the production and delivery of OER content (Pate, 2013; Rhoades et al., 2013). This phenomenon implies that we cannot assume that the growing collection of open online courses is accessible to learners of DCs.

Therefore, in addition to current OER discussions and studies on issues such as implementation and adoption processes involving university faculty (Diallo et al., 2013), and general user perceptions (Hilton, Gaudet, Clark, Robinson, \& Wiley, 2013), there is the need to consider how to better support access to content for the ultimate target end user - the learner, particularly, the learner of a developing country.

\section{OER in Developing Countries}

Global challenges such as poor health, illiteracy, child mortality, and poverty are often foregrounded in dialogue involving developing countries (UNESCO, 2011). Given these challenges, as well as the increasing high costs of higher education, OER advocates argue that the provisions of the concept, through its offerings of seemingly quality education can contribute to the removal of the "unfreedoms" that characterize DCs (Atkins et al., 2007). Thus, the OER concept somewhat assumes that by making content such as open online courses freely available online, the content will be accessible to students of DCs. Further, the OER concept assumes that students of DCs will find available content usable, and that doing so will provide opportunities for the education that these countries need in order to be liberated from poverty.

Students from developing countries, however, have cultural, economic, social, and language characteristics that are different from the currently predominant sources and contexts of open online courses. A case in point is the pervasive use of instructional videos in the delivery of open online courses (Caswell, Henson, Jenson, \& Wiley, 2008; Fowler, 2013). To date however, the large majority of open online course videos, like other OER content, is offered in English and is based on Western ideologies limiting their access and relevance for non-English, non-Western settings (OECD, 2007; Shah, 2013; Trucano, 2013). Even for developing countries where English is an official language, there may be marked differences in the form, cultural, and social contexts of use with regards to factors such as dialect and accent. Learners must have adequate knowledge of the language of instruction in order for the process of learning to occur (Adank \& Janse, 2010; Dunton, Bruce, \& Newton, 2011). Moreover, fundamental to the open education concept is the removal or limiting of barriers to access and use (Atkins et al., 2007; Hylén, 2006; OECD, 2007). There is therefore the need for current leading producers and providers to consider relevant limiting and enabling factors to access.

Access and use of open online courses are affected by economic, technological, social, and legal factors (Atkins et al., 2007; OECD, 2007; Trucano, 2013; Tuomi, 2013). Legally, there are open licensing arrangements in place that permit the free access, use, reuse, and sharing of OER

This work is licensed under a Creative Commons Attribution 4.0 International License. 
(Bissell, 2009; Kanwar et al., 2011). Economic factors involve having the resource means to actually engage in the production, delivery, access and use of OER. For example, for the learner, it involves having the means to acquire or access the necessary computer hardware and software, as well as adequate internet service. Technological factors include the availability of necessary technology solutions and infrastructure such as reliable electricity supply, physical access to computers, the Internet, and adequate Internet bandwidth (OECD, 2007).

The capability and skill to engage in OER, as well as cultural differences constitute social factors (OECD, 2007; Tuomi, 2013). For the learner, a social capability will include having the knowhow to actually use technical features of an open online course video for example. Social capability will also include a learner's ability to comprehend the language used in the open online course instruction. Developing countries have inadequate information and communication technology infrastructure (ITU, 2014), unreliable electricity supply, inadequate quality educational resources, and limited access to higher educational opportunities (UNESCO, 2011). For example, according to the International Telecommunication Union, while an estimated $78 \%$ of people in developed countries used the Internet in 2014, only $32 \%$ of the population in developing countries was estimated to be online (ITU, 2014). Also, while growth rate in mobilebroadband was highest in developing countries, actual subscription was estimated to be $21 \%$ compared to $84 \%$ in developed countries (ITU, 2014).

The challenges of developing countries have made economic, technological, and social factors the most cited in OER dialogue involving those countries, and when they are, the factors are usually identified as significant barriers to OER production, delivery, access, and use (Atkins et al., 2007; Hussain, Chandio, \& Sindher, 2013; Mtebe \& Raisamo, 2014; Trucano, 2013). The often mentioned barriers, however, constitute the same factors that can, with appropriate measures, provide the enablement needed to promote OER in DCs (OECD, 2007). Economic and technological barriers have been longstanding in DCs. Besides, addressing economic and technological barriers in DCs, indeed, falls outside the scope of leading producers and providers of open online courses. Producers and providers cannot be taken to be responsible for the economic and technological challenges of DCs or their students. Economic and technological factors, as defined, will therefore be assumed to be constant in this discussion. From the perspective of learners in developing countries, however, tackling social barriers to access and use of open online courses that cross national borders can reasonably be considered a direct responsibility of current dominant producers and providers (UNESCO, 2005).

To sustain any hopes of achieving the Universal Declaration of Human Rights on equal and universally accessible education (United Nations, 1948), some argue that populations who have the most need for OER should not only be consumers but also producers (Rhoades et al., 2013; Willems \& Bossu, 2012). However, the production of local content in DCs has been minute due to the barriers discussed previously. There are strong power factors relating to the same economic 
and technological barriers that place developing countries at a significant disadvantage when it comes to production of content.

\section{A Need to Consider Learners of Developing Countries}

The discussion thus far makes the issue of learner access of OER content in developing countries pertinent. It also makes addressing social barriers very pressing. The need to consider social challenges becomes more relevant when one considers that open online courses are primarily available through the Internet. Learners must not only have the necessary skills needed to find relevant open online courses from the ocean of the Internet but also the skills to use them. This makes two capabilities, ability to access and ability to use, most relevant within the open online course context. However, the voice of the potential learners in DCs who might access and use open online courses is notably absent in the research and dialogue related to OER to date. This paper contributes to this need by taking a learner's perspective to propose a conceptual framework for producers and providers to consider.

\section{A Three-Level Relationship for Access to Open Online Courses}

This section develops a conceptual representation of the relationship among the open education concept; access to open online courses; barriers to, or enablers of, access; and universal design of online learning. The paper shows, with reference to access and use of open online courses by learners of developing countries, that the factors follow a three-level relationship. The open education concept is at one level as the root, which all OER initiatives should draw from and be founded on; this level is referred to as the open education concept level. Also, primarily, open education aims at making education universally available (Caswell et al., 2008), which cannot be made possible without ensuring access to OER offerings (Huijser, Bedford, \& Bull, 2008). Access to open online courses, is therefore at a first level as the central concept, a level called the access level. A second, referred to as the participation level, caters for the use, modification or repurposing, and redistribution of open online courses. Social and other factors contribute as either barriers or enablers to access at all levels of the relationship.

\section{The Open Concept in Open Education}

Open education is founded on the open concept. Open implies freely accessible, and free to use, modify, and redistribute (Bissell, 2009). Open allows for universal participation with no discrimination or limitation (Bissell, 2009). The open concept is key requiring that any OER, including open online courses, that claims openness does make provision for access to individuals, groups, or any entity. The meaning of openness, therefore, necessitates two fundamental essential requirements: free availability of education resources and the removal or limiting as much as possible of any obstacles to access and use (Atkins et al., 2007; Hylén, 2006; OECD, 2007).

This work is licensed under a Creative Commons Attribution 4.0 International License. 
Tuomi (2013) expounds the open concept within the OER context by distinguishing openness into four levels. Level one or OER 1 is concerned with access and accessibility; OER 2 deals with the right and capability to use; and OER 3 addresses the provisions that allow for users to be able to modify, reuse, and repurpose content, as well as improve their value. Redistribution of resources constitutes OER 4. For example, OER 1 ensures that a learner from a developing country can actually watch and comprehend the language of instruction in an open online course video on Basic Statistics using Excel. OER 2 would account for the learner being able to use the course to meet a particular learning objective, such as being able to perform descriptive statistics of data using Excel. The first two OER levels further lend support to this paper's assertion that access and use are most essential to learners.

Tuomi's levels are seemingly hierarchical, which indicates that level two, for example, is reachable only when one has successfully attained level one. Access, therefore, precedes and is needed for use, while the capability to use is necessary if users can localize, contribute, and add value to an open online course. Thus, as shown in Figure 1, the open education concept takes the base position in the relationship while access takes a central position.

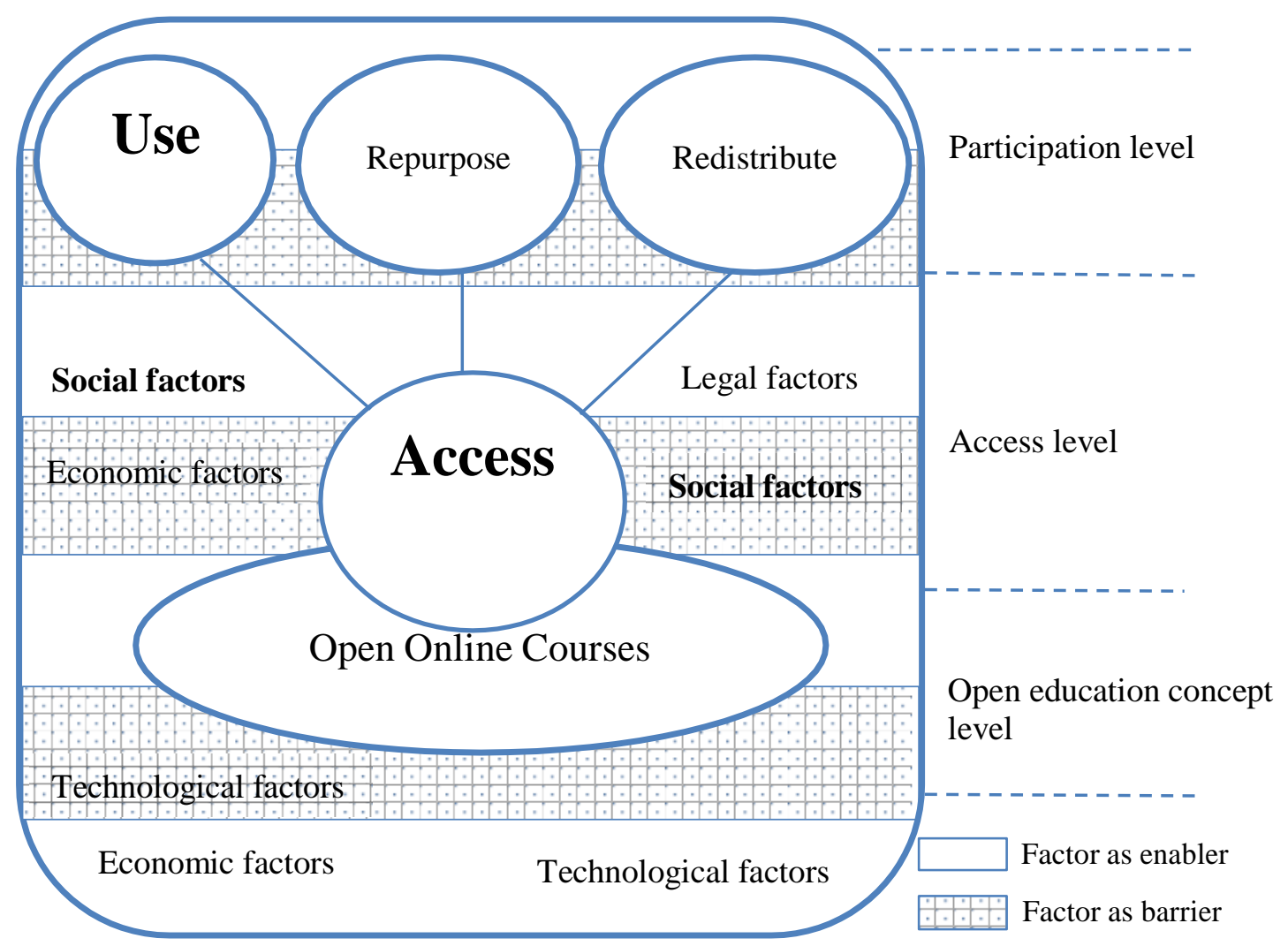

Figure 1. A framework for access to open online courses from the perspective of the learner of a developing country.

This work is licensed under a Creative Commons Attribution 4.0 International License. 
This figure shows a three-level conceptual relationship involving the open education concept, access, and participation in open online courses. Access is central primarily because the relationship assumes the learner's perspective. Also, access is embedded in the open online courses object because the main purpose of the open education concept is to make education universally accessible. Access and use are in boldface because, as the author argues, they are the most relevant from the learner's standpoint. Social factors are also in boldface because it is argued to be the most related to the learner.

\section{Access to Open Online Courses}

The ensuing analysis establishes that for the learner, ensuring access is foremost. Access and accessibility are used interchangeably in this paper. With regards to eLearning, accessibility is defined as the ability of a learning environment to adapt to learner-specific needs and preferences (IMS Global Learning Consortium, 2004). For example, according to the IMS Global Learning Consortium (2010, 2004), an accessible learning environment is amenable to changes to user interfaces and properties of learning resources in order to accommodate any changing needs and preferences of the learner. Regarding content, an accessible learning environment is able to adapt control methods, access modalities, presentations, and learner supports, as well as deliver adequate and equivalent alternatives to meet learner needs (IMS Global Learning Consortium, 2004). In the same vein, disability is not an inherent human characteristic but a mismatch between the affordances of educational offerings and what a learner needs and prefers (IMS Global Learning Consortium, 2010, 2004). A corollary of this definition of learning disability is that, for learners in a developing country, an inability to watch a high definition open online course video due to weak internet bandwidth at their end could be viewed as a disability within the OER context. In similar vein, an inability to use an open course textbook because it was not designed to accommodate for mobile devices, the means through which most residents in DCs access the internet (ITU, 2014), could also be viewed as disabling.

The eLearning view of disability and accessibility has important implications for the production and provision of open online courses. It introduces an essential perspective for producers and providers to consider when designing, developing, and delivering open online courses to also cater for learners who are characterized by limiting economic, technological, and social factors. Additionally, it submits, on their behalf, a strong case for applicability of national and international accessibility standards and requirements for the production and delivery of online learning. For example, for producers and providers of open online courses in the U.S., the 21st Century Communications and Video Accessibility Act of 2010 will apply.

When followed, the definition and provisions of accessibility within the learning context can to a large extent enhance the universality of OER content. It can also help support access to open online courses for learners in developing countries. Eventually, it could provide support for needed improvements in the use, modification, and redistribution of OER content. For the learner therefore, access to open online courses indeed takes the central position in the 
relationship. This is also true because intuitively and as Figure 1 also shows, access is the necessary entry point to all other capabilities that define the OER concept, including use, repurposing, and redistribution of content. These participation capabilities constitute what this paper calls the participation level.

\section{Barriers or Enablers of Access}

With reference to access to open online courses, economic, technological, and social factors play dual and opposite roles. The legal factor, however, is considered to play only an enabling role because it is what makes OER possible in the first place. Producers and providers of educational resources are under no obligation to make content open; making a resource open is purely voluntary. Once a course becomes an open online course, it is open and available to all provided it is accessible. As a result, Figure 1 indicates legal factors as enablers only. A similar case, however, cannot be made for the other factors. What this implies is that economic, technological, and social factors, at each point, play either an enabling or limiting role.

Economic, technological, and social factors, in themselves, are neither enablers nor barriers but their availability or lack is what makes them either enablers or barriers respectively. For example, while information and communication technologies (ICTs) provide the main means for producing, accessing, and participating in open online courses (Atkins et al., 2007), technology is often cited as a barrier in developing countries because relatively, DCs lack adequate and reliable ICTs. Developing countries are also identified with social barriers because relatively, they lack the economic and technology resources needed to develop the social capabilities and skills needed to participate in open online courses. Additionally, since the majority of open online courses is produced in contexts foreign to DCs, students from DCs are further limited in access and participation by social factors such as culture and language (OECD, 2007; Shah, 2013; Trucano, 2013).

The point here is that the duality of economic, technological, and social factors implies that we are able, with appropriate measures, to turn what are often identified as barriers to access and participation into enablers. For example, there are current multimedia technologies, such as interactive video transcripts, that could be adapted to possibly minimize the social limitation of multilingualism in open online course instructional videos. Interactive video transcripts (IVT) allow for the simultaneous reading and listening of online videos. Also, students can select or click any word or part of an IVT and skip to the specific point in the video. Therefore, where spoken language in an open online course video is not readily familiar, IVT could support students in their listening comprehension. Also, according to the redundancy principle by Clark and Mayer (2011), in special situations such as where language is a limitation, tools such as IVT could promote better learning by making use of the dual-channel human memory modality. Learning design that makes use of the dual-channel memory, verbal and imagery human senses, has been shown to promote learning better than designs that use either the verbal or imagery sense alone (Clark \& Mayer, 2011; Clark \& Paivio, 1991).

This work is licensed under a Creative Commons Attribution 4.0 International License. 


\section{Universal Design of Open Online Courses}

The key message here is, consider the perspective of the learner and design for access. Access is a necessary step towards reaching all participation capabilities of any OER content. The goal of this discussion is not to provide an exposition of universal design principles for online or eLearning. Several sources provide a more focal discussion on the subject (Burgstahler, Corrigan, \& McCarter, 2004; Elias, 2011, 2010; Seale \& Cooper, 2010). It is rather the purpose of this discussion to emphasize to current producers and providers of open online courses, who aim to reach a relatively hard to reach learner-group, the importance of incorporating universal learning design principles to help support access.

When designing for accessibility, consider that in the open online course context, disability and accessibility maintain somewhat different and broader definitions as explained in section 3.2. The author is not discounting the crucial role participation plays in the OER concept. However, for the learner role, access and use are paramount. To help support learner access therefore, there is the need to pay special attention to limiting social and associated barriers to access to open online courses. For example, can the mobile device of a learner in a developing country play an open online course video given the very limited network bandwidth or slow internet speed? For many, if not the majority, of citizens of DCs, mobile-cellular devices, usually with small screen sizes, are the only means of accessing the internet. Developing countries are home to greater than $75 \%$ of mobile-cellular subscriptions in the world as well as the fastest mobile broadband diffusion (ITU, 2014). However, compared to $78 \%$ in developed countries, only $31 \%$ of households in DCs were projected to be connected to the internet by the end of 2014, with only one in ten households in Africa connected (ITU, 2014). Further, fixed (wired) broadband speeds in a greater number of DCs ranged from $256 \mathrm{Kbit} / \mathrm{s}$ to $2 \mathrm{Mbit} / \mathrm{s}$ compared to greater than $2 \mathrm{Mbit} / \mathrm{s}$ in other countries and upwards of $10 \mathrm{Mbit} / \mathrm{s}$ in some developed countries (ITU, 2014). Given such circumstances, the same open online course provided in different bandwidths and for different device-platforms without compromising much quality would suffice.

Socially, instructional content may be so culturally distant that learners find it difficult to follow. Also, although English may be the first language in a developing country, the English accent of an open online course instructor could be unfamiliar and hence unintelligible to students. It would be unreasonable to expect instructors who, for example, offer open online courses to adapt their speaking to students worldwide. Efforts have been made in some quarters to translate open online course instruction from English to other languages. However, this approach cannot only be exacting but also tends to be skewed towards certain known non-English groups, particularly those who have strong presence in the countries that have the most producers and providers of open online courses. For example, as of 2014, MIT's open courseware had translations in Spanish, Portuguese, Chinese, Thai, Persian, Korean, and Turkish (MIT, n.d.). Will translation be done for a language spoken in a community in Southeast Asia or Africa? Translation, notwithstanding, may not be that ideal. For example, Vaid (1988) found support for the position that word 
translation is not the best intervention for second language listening (as cited in Clarke \& Paivio, 1991). Additionally, it is very possible that for some nonnative English speaking developing countries, there are no equivalencies for certain academic and technical words. Learners must be able to follow the language of instruction in order for access and use to occur. These factors raise equity concerns and potentially undermine the claim of universal access to information and knowledge championed by the OER movement.

Social challenges call for the adoption of communication and multimedia learning design theories and principles. A good number of which are already advocated through established web learning design accessibility standards; examples include the $\mathrm{W}_{3} \mathrm{C}$ Web Content Accessibility Guidelines and the IMS Accessibility Project by the IMS Global Learning Consortium. While some current producers and providers of open online courses incorporate these standards to some extent, others do not. For example, at the time of this writing and with reference to open online course videos, some providers such as Khan Academy and edX, used the YouTube platform and therefore had the accessibility features that YouTube offered. edX also provided interactive video transcripts. However, the author did not find videos from providers such as Canvas Network and Udemy to have recommended accessibility features including captions, speech transcripts, video speed control, and different video qualities. This author recommends that producers and providers of open online courses should follow web and multimedia learning standards. This is not only because they are standards and sometimes legal requirements, but more so for the unique definitions of accessibility and disability in the learning context.

\section{Concluding Remarks}

This paper paid specific attention to the learner of a developing country to develop a three-level conceptual framework. The framework involves the open education concept as foundational, access to open online courses as central, and participation in open online courses as dependent on access. The framework was developed based on discussion that involved an analysis of the open education concept, the role of access in OER context, the limiting and enabling factors that affect access to OER content, and relevant universal design principles for online learning. The position of this paper was that for the learner, and the learner of a developing country in particular, being able to access and use OER content such as open online courses are paramount. Supporting access and use of open online courses for learners of developing countries, therefore, requires an understanding of the aforementioned conceptual elements that come into play in the production and provision of open online courses. Making higher educational content freely available online is not enough. As a result, it is recommended to producers and providers who truly seek to make their higher education content open, also to learners in developing countries, to consider the following:

- The historical and original contexts and purposes of the OER concept.

This work is licensed under a Creative Commons Attribution 4.0 International License. 
- The provisions and objectives of the OER concept should inform the design, development, and delivery of open online courses.

- Access and use are the most relevant to the learner.

- Access is needed to allow for participation in all OER content.

- Accessibility and disability have unique definitions within the learning context.

- Follow universal as well as legal requirements and standards for online learning.

- Access to, use of, and participation in open online courses are affected by economic, technological, and importantly, social factors, all of which play dual and opposite roles.

The submission in this paper has referred mainly to online courses that were developed from the outset to be used for open education. However, in the case of formal campus courses, when the decision is also made to share content openly online, the delivery and original design of course materials should be carefully reconsidered. This is because the more open the access of a course online, the more heterogeneous the needs of target learners with respect to social, language, and technological factors. Considerations should therefore be made in light of the recommendations made in this paper as well as cross-border education guidelines such as the guidelines for sharing quality higher education across borders (UNESCO, 2005).

The key message here has been produce, provide, and deliver open online courses for access and use. The concluding remarks in this paper were based on conceptual analyses of certain critical factors. Future research should consider actual scientific examinations of some of the assertions made in this paper. For example, the author argued that with reference to language, providing universal design features such as interactive video transcripts with open online course videos could help with supporting access with respect to language limitations. This assertion should be empirically examined for validity. Additionally, the assertion that social factors are the most relevant to learners can also be studied empirically, either through qualitative or quantitative methods. Such studies may contribute to much needed scientific studies within the OER context (Hilton et al., 2013). The purpose of the OER movement is to ensure "no-cost access, use, adaptation and redistribution by others with no or limited restrictions" (UNESCO, 2012, p. 1). Overall, iteratively using the results of empirical studies to refine the production and provision of open online courses may contribute to drawing us closer to ensuring access, use, and participation by learners of developing countries. 


\section{Acknowledgement}

I would like to thank Dr. Robert Branch for his invaluable feedback on the manuscript. I am also grateful to my colleagues at the University of Georgia who provided feedback at various stages of the manuscript development process.

\section{References}

Adank, P., \& Janse, E. (2010). Comprehension of a novel accent by young and older listeners. Psychology and Aging, 25(3), 736-740.

Atkins, D. E., Brown, J. S., \& Hammond, A. L. (2007). A review of the open educational resources (OER) movement: Achievements, challenges, and new opportunities. Retrieved April 2015 from http://www.hewlett.org/uploads/files/ReviewoftheOERMovement.pdf

Bissell, A. N. (2009). Permission granted: Open licensing for educational resources. Open Learning,24(1), 97-106.

Burgstahler, S., Corrigan, B., \& McCarter, J. (2004). Making distance learning courses accessible to students and instructors with disabilities: A case study. Internet and Higher Education, 7, 233-246.

Caswell T., Henson, S., Jenson, M., \& Wiley, D. (2008). Open educational resources: Enabling universal education. The International Review of Research in Open and Distance Learning, 9(1), 1-7.

Clark, R. C., \& Mayer, R. E. (2011). e-learning and the science of instruction. San Francisco, CA: Pfeiffer.

Clark, J. M., \& Paivio, A. (1991). Dual coding theory and education. Educational Psychology Review, 3, 149-210.

Coursera. (2014, January 17). Our student numbers. Retrieved April 2015 from https://www.coursera.org/about/community

Coursera. (2013, October 23). With 13 new organizations, Coursera reaches 100 partners milestone! Retrieved April 2015 from http://blog.coursera.org/post/64905875290/

Diallo, B., Thuo, C. W., \& Wright, C. R. (2013). Approaches to the production and use of OER: The african virtual university experience. In McGreal, R., Kinuthia, W., \& Marshall, S. (Eds.).

This work is licensed under a Creative Commons Attribution 4.0 International License. 
Open educational resources: Innovation, research and practice (pp. 91-103). Vancouver, BC: Commonwealth of Learning and Athabasca University.

Donkor, P. (May 2011). Developing and using open educational resources at KNUST. Educational Technology Debate. Retrieved April 2015 from http://edutechdebate.org/digitallearning-resources/

Dunton, J., Bruce, C., \& Newton, C. (2011). Investigating the impact of unfamiliar speaker accent on auditory comprehension in adults with aphasia. International Journal of Language \& Communication Disorders, 46, 63-73.

Elias, T. (2011). Universal instructional design principles for mobile learning. The International Review of Research in Open and Distance Learning, 12(2), 143-156.

Elias, T. (2010). Universal instructional design principles for Moodle. The International Review of Research in Open and Distance Learning, 11(2), 1-9.

Fowler, G. A. (2013, October 8). An early report card on massive open online courses. The Wall Street Journal. Retrieved May 2015 from http://www.wsj.com/articles/SB10001424052702303759604579093400834738972

Hilton, J. L., Gaudet, D., Clark, P., Robinson, J., \& Wiley. D. (2013). The adoption of open educational resources by one community college math department. The International Review of Research in Open and Distance Learning, 14(4), 37-50.

Huijser, H. J., Bedford, T., \& Bull, D. (2008). OpenCourseWare, global access and the right to education: Real access or marketing ploy? The International Review of Research in Open and Distributed Learning, 9(1).

Hussain, I., Chandio, J. H., \& Sindher, R. H. K. (2013). A study on attitude of university academia towards the use of open educational resources in higher education. Pakistan Journal of Commerce and Social Sciences, 7(2), 367-380.

Hylén, J. (2006). Open educational resources: Opportunities and challenges. Paris: OECD's Center for Educational Research and Innovation.

International Telecommunication Union. (May 2015). ICT facts and figures - The world in 2015 . Retrieved August 8, 2015, from http://www.itu.int/en/ITUD/Statistics/Documents/facts/ICTFactsFigures2015.pdf

IMS Global Learning Consortium. (2010, April 30). IMS access for all personal needs and preferences description for digital delivery information model. Retrieved April 2015 from This work is licensed under a Creative Commons Attribution 4.0 International License. 
http://www.imsglobal.org/accessibility/accpnpv2po/spec/ISO ACCPNPinfoModelv2po. $\underline{h t m l}$

IMS Global Learning Consortium (2004, July 12). IMS access for all meta-data overview. Retrieved April 2015 from http://www.imsglobal.org/accessibility/accmdv1po/imsaccmd oviewv1po.html

International Association of Universities. (2006). Sharing quality higher education across borders: A checklist for good practice. Retrieved August 2015 from http://www.iauaiu.net/content/policy-statements-o

Kamper, G. D., \& Du Plessis, E. C. (2014). Some critical reflections on open distance learning, with particular reference to work-integrated learning. Africa Education Review, 11(1), 7790.

Kanwar, A., Uvalić-Trumbić, S., \& Butcher, N. (2011). A basic guide to open educational resources (OER). Vancouver: Commonwealth of Learning; Paris: UNESCO.

MIT. (n.d.). Our History. Retrieved April 2015 from http://ocw.mit.edu/about/our-history/

Mtebe, J. S., \& Raisamo, R. (2014). Investigating perceived barriers to the use of open educational resources in higher education in Tanzania. The International Review of Research in Open and Distance Learning, 15(2), 43-65.

Murphy, R., Gallagher, L., Krumm, A. E., Mislevy, J., \& Hafter, A. (2014 March). Research on the use of Khan Academy in schools. Retrieved April 2015 from http://www.sri.com/work/publications/research-use-khan-academy-schools-research$\underline{\text { brief }}$

OECD. (2007). Giving knowledge for free: The emergence of open educational resources. Paris: OECD Center for Educational Research and Innovation. Retrieved December 2014 from http://www.oecd.org/edu/ceri/38654317.pdf

Pate, R. L. (2013). MOOCs and modern democracies. Contemporary Readings in Law and Social Justice, 5(2), 39-49.

Richter, T., \& McPherson, M. (2012). Open educational resources: education for the world? Distance education, 33(2), 201-219.

Rhoads, R. A., Berdan, J., \& Toven-Lindsey, B. (2013). The open courseware movement in higher education: Unmasking power and raising questions about the movement's democratic potential. Educational Theory, 63, 87-109.

Seale, J., \& Cooper, M. (2010). E-learning and accessibility: An exploration of the potential role of This work is licensed under a Creative Commons Attribution 4.0 International License. 
generic pedagogical tools. Computers \& Education, 54, 1107-1116

Shah, D. (2013, December 22). MOOCs in 2013: Breaking down the numbers. Retrieved April 2015 from https://www.edsurge.com/n/2013-12-22-moocs-in-2013-breaking-down-thenumbers

Trucano, M. (2013, November 12). More about MOOCs and developing countries. EduTech.

Retrieved December 2014 from http://blogs.worldbank.org/edutech/moocs-developing$\underline{\text { countries }}$

Tuomi, I. (2013). Open educational resources and the transformation of education. European Journal of Education, 48, 58-78.

UNESCO. (2002, July 1-3). Forum on the impact of open courseware for higher education in developing countries (CI-2002/CONF.803/CLD.1). Paris: UNESCO. Retrieved May 2015 from http://unesdoc.unesco.org/images/o012/001285/128515e.pdf

UNESCO. (2005). Guidelines for quality provision in cross-border higher education (ED2005/WS/76). Paris: UNESCO. Retrieved May 2015 from http://www.unesco.org/education/guidelines E.indd.pdf

UNESCO. (2011). Building Human Capacities in Least Developed Countries to Promote Poverty Eradication and Sustainable Development. Paris: UNESCO. Retrieved May 2015 from http://unesdoc.unesco.org/images/o019/001915/191597e.pdf

UNESCO. (2012). 2012 Paris OER Declaration. Paris: UNESCO. Retrieved May 2015 from http://www.unesco.org/new/fileadmin/MULTIMEDIA/HQ/CI/CI/pdf/Events/English Paris_OER_Declaration.pdf

United Nations (1948). The universal declaration of human rights. Retrieved August 2014 from http://www.un.org/en/documents/udhr/

Willems, J., \& Bossu, C. (2012). Equity considerations for open educational resources in the glocalization of education. Distance Education, 33(2), 185-199.

\section{Athabasca University $\mathbf{A}$}

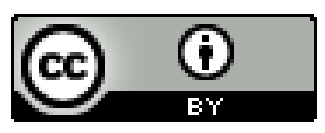

This work is licensed under a Creative Commons Attribution 4.0 International License. 